\title{
Pacific Atmospheric Sulfur Experiment (PASE): dynamics and chemistry of the south Pacific tropical trade wind regime
}

\author{
Alan Bandy • Ian C. Faloona • Byron W. Blomquist • Barry J. Huebert • \\ Antony D. Clarke • Steven G. Howell • R. L. Mauldin • Christopher A. Cantrell • \\ James G. Hudson • Brian G. Heikes • John T. Merrill • Yuhang Wang • \\ Daniel W. O'Sullivan • Wolfgang Nadler • Douglas D. Davis
}

Received: 17 March 2011 / Accepted: 16 November 2011 /

Published online: 15 February 2012

C The Author(s) 2012. This article is published with open access at Springerlink.com

\begin{abstract}
The Pacific Atmospheric Sulfur Experiment (PASE) was a comprehensive airborne study of the chemistry and dynamics of the tropical trade wind regime (TWR) east of the island of Kiritibati (Christmas Island, $157^{\circ}, 20^{\prime} \mathrm{W}, 2^{\circ} 52^{\prime} \mathrm{N}$ ). Christmas Island is located due south of Hawaii. Geographically it is in the northern hemisphere yet it is $6-12^{\circ}$ south of the intertropical convergence zone (ITCZ) which places it in the southern
\end{abstract}

Dr. Alan Bandy deceased.

A. Bandy $\cdot$ W. Nadler

Drexel University, Philadelphia, PA, USA

I. C. Faloona $(\bowtie)$

University of California Davis, Davis, CA, USA

e-mail: icfaloona@ucdavis.edu

B. W. Blomquist • B. J. Huebert • A. D. Clarke • S. G. Howell

University of Hawaii, Honolulu, HI, USA

R. L. Mauldin

Department of Physics, University of Helsinki, Helsinki 00014, Finland

C. A. Cantrell

Atmospheric Chemistry Division, National Center for Atmospheric Research, Boulder, CO, USA

J. G. Hudson

Desert Research Institute, Reno, NV, USA

B. G. Heikes $\cdot$ J. T. Merrill

University of Rhode Island, Narragansett, RI, USA

Y. Wang $\cdot$ D. D. Davis

Georgia Institute of Technology, Atlanta, GA, USA

D. W. O'Sullivan

U.S. Naval Academy, Annapolis, MD, USA 
hemisphere meteorologically. Christmas Island trade winds in August and September are from east south east at $3-15 \mathrm{~ms}^{-1}$. Clouds, if present, are fair weather cumulus located in the middle layer of the TWR which is frequently labeled the buffer layer (BuL). PASE provided clear support for the idea that small particles $(80 \mathrm{~nm})$ were subsiding into the tropical trade wind regime (TWR) where sulfur chemistry transformed them to larger particles. Sulfur chemistry promoted the growth of some of these particles until they were large enough to activate to cloud drops. This process, promoted by sulfur chemistry, can produce a cooling effect due to the increase in cloud droplet density and changes in cloud droplet size. These increases in particle size observed in PASE promote additional cooling due to direct scattering from the aerosol. These potential impacts on the radiation balance in the TWR are enhanced by the high solar irradiance and ocean albedo of the TWR. Finally because of the large area involved there is a large factional impact on earth's radiation budget. The TWR region near Christmas Island appears to be similar to the TWR that persists in August and September, from southwest of the Galapagos to at least Christmas Island. Transport in the TWR between the Galapagos and Christmas involves very little precipitation which could have removed the aerosol thus explaining at least in part the high concentrations of $\mathrm{CCN}(\approx 300$ at $0.5 \%$ supersaturation) observed in PASE. As expected the chemistry of sulfur in the trade winds was found to be initiated by the emission of DMS into the convective boundary layer (BL, the lowest of three layers). However, the efficiency with which this DMS is converted to $\mathrm{SO}_{2}$ has been brought into further question by this study. This unusual result has come about as result of our using two totally different approaches for addressing this long standing question. In the first approach, based on accepted kinetic rate constants and detailed steps for the oxidation of DMS reflecting detailed laboratory studies, a DMS to $\mathrm{SO}_{2}$ conversion efficiency of $60-73 \%$ was determined. This range of values lies well within the uncertainties of previous studies. However, using a completely different approach, involving a budget analysis, a conversion value of $100 \%$ was estimated. The latter value, to be consistent with all other sulfur studies, requires the existence of a completely independent sulfur source which would emit into the atmosphere at a source strength approximately half that measured for DMS under tropical Pacific conditions. At this time, however, there is no credible scientific observation that identifies what this source might be. Thus, the current study has opened for future scientific investigation the major question: is there yet another major tropical marine source of sulfur? Of equal importance, then, is the related question, is our global sulfur budget significantly in error due to the existence of an unknown marine source of sulfur? Pivotal to both questions may be gaining greater insight about the intermediate DMS oxidation species, DMSO, for which rather unusual measurements have been reported in previous marine sulfur studies. The 3 pptv bromine deficit observed in PASE must be lost over the lifetime of the aerosol which is a few days. This observation suggests that the primary $\mathrm{BrO}$ production rate is very small. However, considering the uncertainties in these observations and the possible importance of secondary production of bromine radicals through aerosol surface reactions, to completely rule out the importance of bromine chemistry under tropical conditions at this time cannot be justified. This point has been brought into focus from prior work that even at levels of $1 \mathrm{pptv}$, the effect of $\mathrm{BrO}$ oxidation on DMS can still be quite significant. Thus, as in the case of DMS conversion to $\mathrm{SO}_{2}$, future studies will be needed. In the latter case there will need to be a specific focus on halogen chemistry. Such studies clearly must involve specific measurements of radical species such as $\mathrm{BrO}$.

Keywords Chemistry · Dynamics · Tropical · Trade wind · Aerosol $\cdot \mathrm{CCN} \cdot \mathrm{CN} \cdot \mathrm{SO}_{2}$. DMS $\cdot \mathrm{H}_{2} \mathrm{SO}_{4} \cdot \mathrm{MSA} \cdot \mathrm{H}_{2} \mathrm{O}_{2} \cdot \mathrm{CH}_{3} \mathrm{OOH} \cdot \mathrm{Pacific} \cdot \mathrm{SO}_{4}^{2-}$ 


\section{Introduction}

The Pacific Atmospheric Sulfur Experiment (PASE) was a comprehensive study of the chemistry of a trade wind regime (TWR) of the tropical Pacific near $157^{\circ}, 20^{\prime} \mathrm{W}$, $2^{\circ} 52^{\prime} \mathrm{N}$ (Christmas Island, Kiritibati) flown in August and September of 2007 on the NSF/NCAR C130. To reduce the complexity of the field observations, PASE focused on the chemistry, microphysics and dynamics of the cloud free convective boundary layer (BL).

The tropical trades play an important role in earth's climatology because they overlay a large area of the ocean having a very small albedo and a high solar irradiance. A GOES satellite photograph taken on the day of RF05 is shown in Fig. 1. PASE was conducted just east of Christmas Island in a relatively cloud free region.

A major goal of PASE was to study the chemistry occurring in the TWR that may influence cloud droplet chemistry and aerosol concentrations and composition. Aerosol size, number, chemistry and surface areas are key characteristics that influence their role in boundary layer processes associated with nucleation, gas to particle conversion and their activation as cloud condensation nuclei $(\mathrm{CCN})$. Aerosol sources include direct injection of sea-salt from the ocean surface, entrainment from the free troposphere and in-situ nucleation. The process of aerosol growth via the accretion of gases such as water vapor and sulfuric acid $\left(\mathrm{H}_{2} \mathrm{SO}_{4}\right)$ can add mass while conserving number. In-cloud, collision-coalescence and

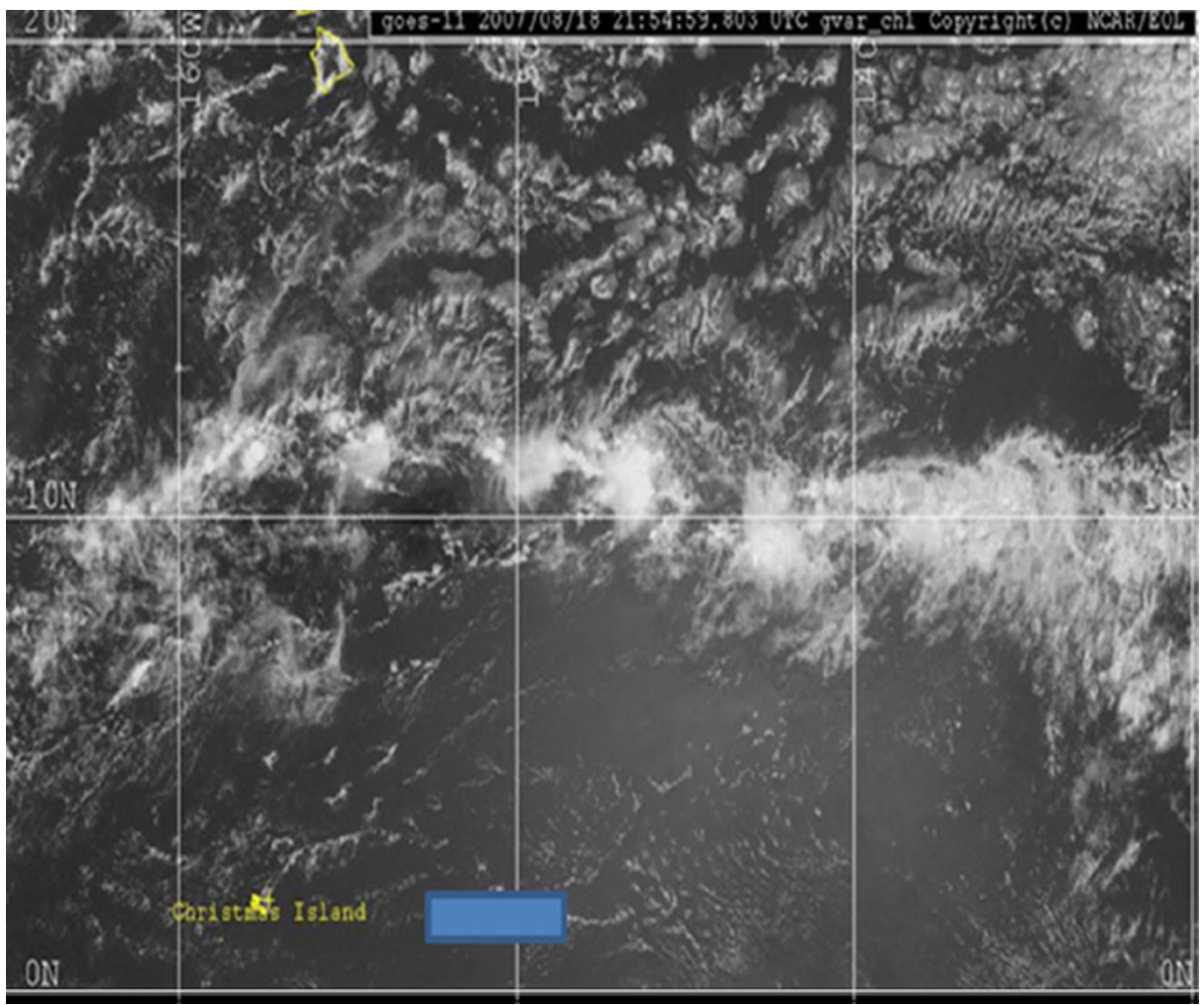

Fig. 1 GOES visible photograph of the PASE study region (shown as a blue rectangle) 
sedimentation can alter number, chemical properties, mass and shape of the size distributions. These influences may, in turn, modulate overall cloud albedo. Cloud convection and scavenging can also introduce gases, aerosols and water vapor into the free troposphere (FT) over the intertropical convergence zone (ITCZ) (Clarke et al. 1999) but is thought to be negligible in the TWR due to strong subsidence.

Since the discovery that dimethyl sulfide (DMS) is emitted in large quantities from the ocean (Barnard et al. 1982), speculation has abounded that DMS plays an important role in climate (Charlson et al. 1987). Atmospheric DMS oxidation is initiated mainly by $\mathrm{OH}$ in the remote marine environment to produce $\mathrm{SO}_{2}$ which in turn is oxidized both homogeneously and heterogeneously to $\mathrm{H}_{2} \mathrm{SO}_{4}$ (Chen et al. 2000; Davis et al. 1999). Aerosol can accrete $\mathrm{H}_{2} \mathrm{SO}_{4}, \mathrm{NH}_{3}$ and $\mathrm{H}_{2} \mathrm{O}$ to form larger particles that scatter sunlight or act as cloud condensation nuclei $(\mathrm{CCN})$ that affect cloud physical and chemical characteristics. Finally, under favorable conditions with low aerosol surface area, there is evidence that DMS chemistry can lead to the formation of new particles (Clarke et al. 1998).

Previous studies involving more limited suites of instruments have produced valuable but fragmented information on TWR chemistry. One of these, a 1994 study on Christmas Island (Bandy et al. 1996), produced $\mathrm{SO}_{2}$ and DMS time series that unequivocally showed that DMS was oxidized to $\mathrm{SO}_{2}$. Non-sea salt sulfate (NSS) and methane sulfonate (MS) also had diurnal variations (Huebert et al. 1996). Pacific Exploration Missions- Tropics A and B and Aerosol Characterization Experiment 1 were the first airborne studies containing a large suite of instruments including $\mathrm{H}_{2} \mathrm{SO}_{4}, \mathrm{OH}$, methane sulfonic acid (MSA), $\mathrm{NO}, \mathrm{O}_{3}, \mathrm{SO}_{2}$ and DMS. In addition to further confirming that DMS oxidation produces $\mathrm{SO}_{2}$, these programs showed that $\mathrm{OH}$ was one of the main oxidants and that $\mathrm{H}_{2} \mathrm{SO}_{4}$ was one of the principal products. They left unanswered the role of the intermediate DMSO.

Previous experiments demonstrated the importance of nucleation from sulfuric acid in cloud outflow from deep convection as a source of new particles to the free troposphere. They also included a rare example of nucleation at the top of the boundary layer linked to sulfur chemistry after deep convection and precipitation had removed most aerosol surface area in the MBL (Clarke et al. 1999).

\section{PASE experiment details}

\subsection{The study region}

The Christmas Island area was selected for study because it was meteorologically and chemically the simplest TWR system that could be easily reached and studied using aircraft. It is representative of many other tropical trade regimes so knowledge gained at Christmas Island can be extrapolated to a very large area of the tropical ocean.

The climatology of the study region and its fetch was characterized by extremely low rainfall $\left(\sim 1 \mathrm{~mm}\right.$ day $\left.^{-1}\right)$ during Aug./Sept. stretching all the way back to the stratocumulus region off the coast of South America. Figure 2 shows the precipitation estimates made by the Tropical Rainfall Measuring Mission (TRMM) satellite data for the period of the mission, along with the mean $10 \mathrm{~m}$ winds from SeaWinds on NASA's Quick Scatterometer. The PASE experiment is clearly situated near the end of a long, arid fetch that ultimately feeds into the ITCZ. Tradewind cumulus are the dominant clouds in the region embedded in the prevailing southeasterly trade winds averaging $8 \mathrm{~ms}^{-1}$ near the surface. An example of the vertical structure of the lower troposphere sampled during PASE is shown in Fig. 3 (RF02). The region between the 


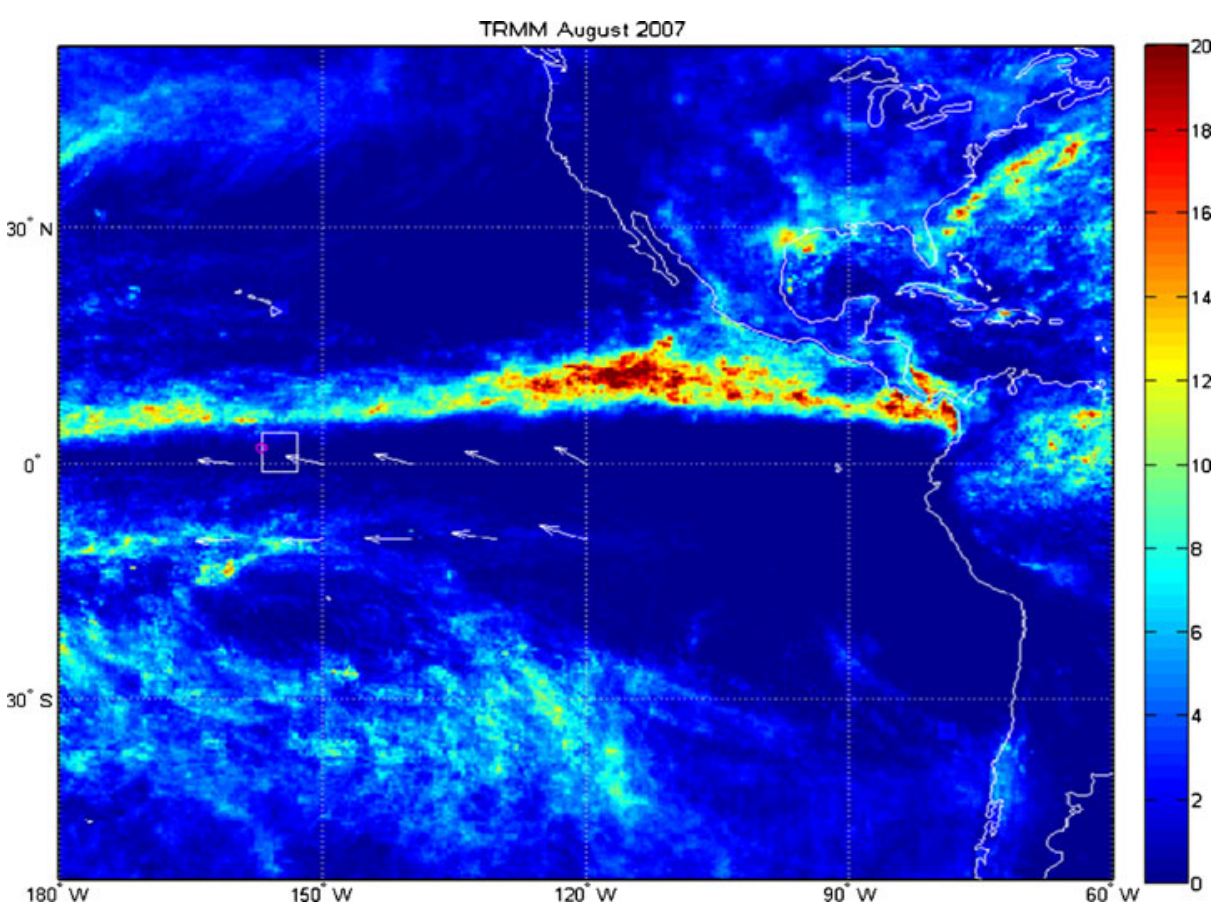

Fig. 2 Daily rainfall $\left(\mathrm{mm} \mathrm{hr}^{-1}\right)$ for the PASE flight region during the month of August 2007 from TRMM overlaid with QuikSCAT surface winds. The white box encloses the flight area and the pink circle represents the approximate location of Christmas Island

horizontal pink lines is the BuL defined by $\mathrm{z}_{\mathrm{i}}$, the base of the lowest (usually fairly weak) inversion, and the tradewind inversion height (TWI) at the top. In contrast to the BL, where all three scalars are well mixed, the BuL contains a more stratified, conditionally unstable structure where mixing ratios fall off (for bottom-up scalars like DMS and water vapor) or increase (for
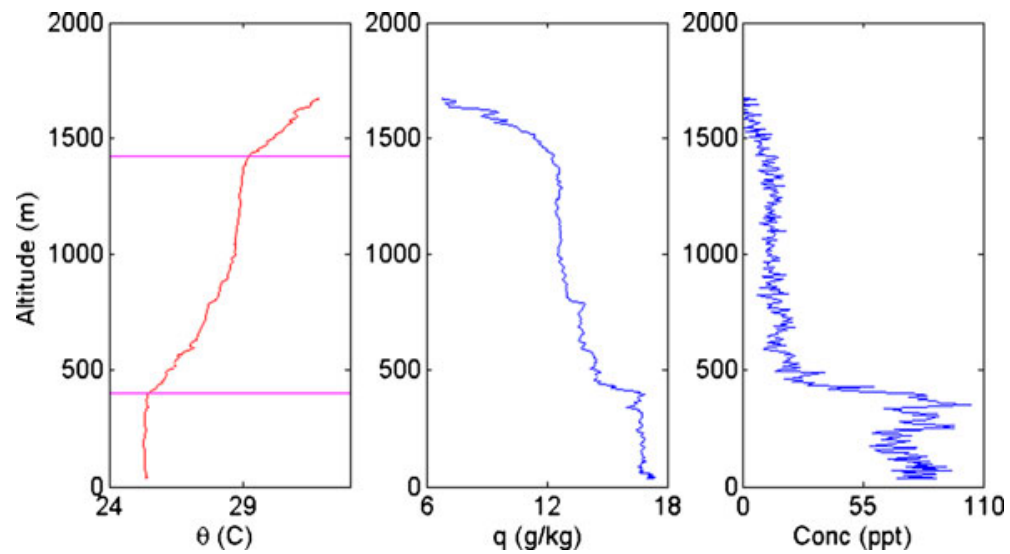

Fig. 3 Profile leg from the second research flight (RF02) showing potential temperature, water vapor (q) and dimethyl sulfide (DMS) (labeled conc. The first pink line is the top of the BL and the bottom of the BuL. The second pink line is the top of the BuL and the bottom of the FT 


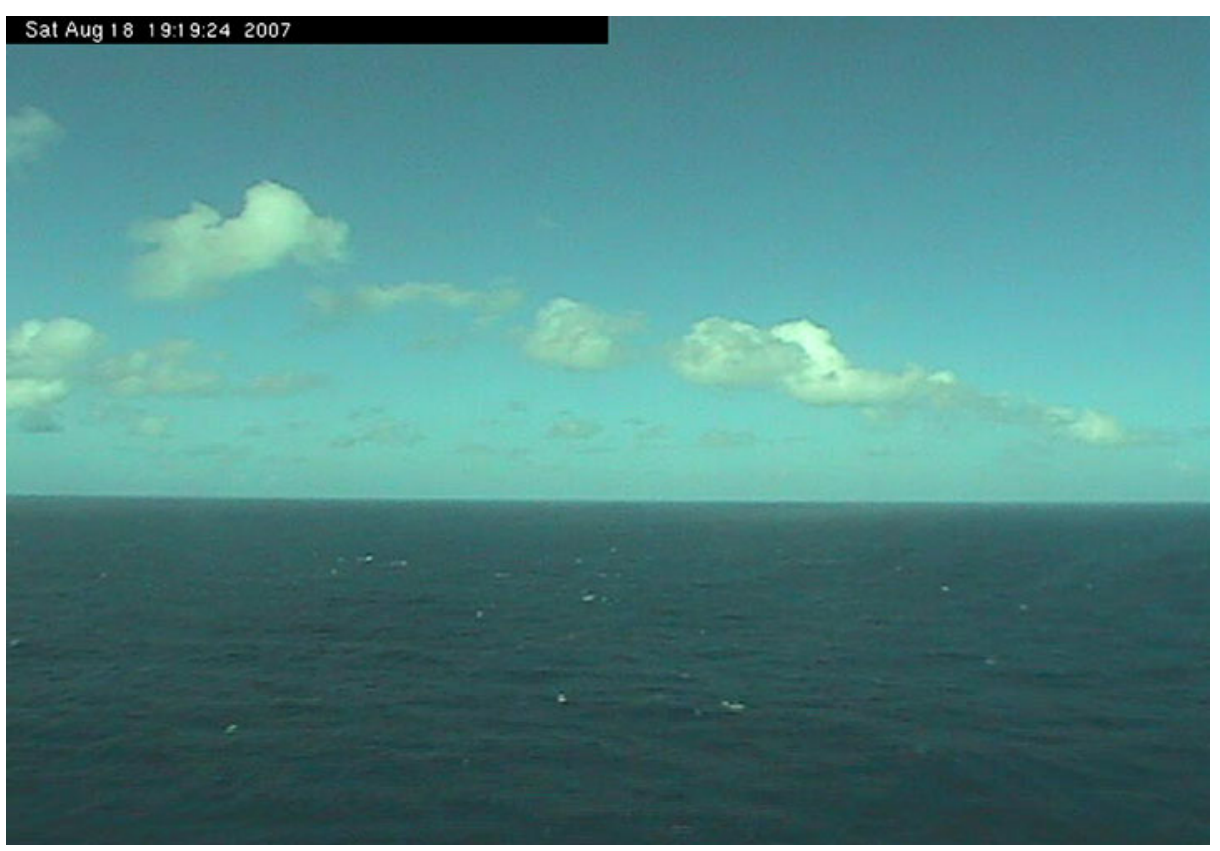

Fig. 4 Photograph of low level clouds on RF05 taken at $30 \mathrm{~m}$ from C130

top-down scalars like ozone) steadily with height. Measurements of liquid water throughout the experiment show a bimodal structure to the cloud field with a primary peak (approximately $15 \%$ cloud cover) near the top of the BuL (base of the TWI) and a secondary peak near onequarter depth of the BuL (approximately $200 \mathrm{~m}$ above $\mathrm{z}_{\mathrm{i}}$ ). A photograph of the clouds present in the RF05 study area is shown in Fig. 4.

The sea-air temperature difference averaged $2.5 \mathrm{~K}$ during PASE and the observed Bowen ratios were low $(0.05 \pm 0.025)$. Nevertheless the mean stability parameter $\left(\mathrm{z}_{\mathrm{i}} / \mathrm{L}\right.$, where $\mathrm{L}$ is the Obukhov Length), for the $\mathrm{BL}$ was -3.8 indicating moderately convective boundary layers. Although turbulence in the BuL was much more variable and intermittent, budgets of the turbulent kinetic energy (TKE) reveal that nearly equal parts buoyancy, transport, and shear production sustain TKE in the BuL, on average, at $\sim 70 \%$ the levels measured in the convective BL. Throughout the mission, sea surface temperatures obtained from the $\mathrm{C} 130$ data set, declined gradually due to an encroaching tropical wave instability accompanied by greater phytoplankton productivity, stronger winds, and a subsiding TWI in the region. Moreover, on nearly three-quarters of the flights a low level jet, at least $2 \mathrm{~ms}^{-1}$ in excess of the mean, was observed in the BuL. By evaluating the ratio of BuL to BL mixing ratios for compounds with known chemical lifetimes (DMS and $\mathrm{O}_{3}$ ) an average mixing time in the BuL was found to be about $30 \mathrm{~h}$.

\subsection{Experiment description}

RF01, RF02, and RF12 were flown as circles advected with the mean wind. Flights RF03 and RF05 through RF14 were flown as more or less stationary chevron patterns to minimize contamination of the study region by aircraft exhaust. Flights RF01, RF02, RF06, RF08, RF09, RF12, RF13, and RF14 were flown with the altitude pattern designed for determining chemical 
budgets. Most flights consisted of three stacks each made up of three 30 min legs in the BL (below $500 \mathrm{~m}$ ) and one $30 \mathrm{~min}$ leg in the BuL just above the BL top (about $500 \mathrm{~m}$ ). Chemistry near the ocean surface was studied in research flights $5,7,10$, and 11 . Thirty minute legs were flown at approximately 30,100 and $150 \mathrm{~m}$. Flights 6 and 13 were nighttime budget studies beginning at about $3 \mathrm{AM}$ local time. The first $30 \mathrm{~m}$ level was flown just after sunrise for safety reasons. RF04 was a search for nucleation at cloud top in the more convective region to the north and had a complex profile.

\subsection{Measurements}

Fast instruments were used to make accurate and high speed airborne determinations of $\mathrm{SO}_{2}$, DMS, methane sulfonic acid (MSA), $\mathrm{H}_{2} \mathrm{SO}_{4}, \mathrm{OH}$, peroxyl radical $\left(\mathrm{HO}_{2}\right)$, water vapor $\left(\mathrm{H}_{2} \mathrm{O}\right)$, ozone $\left(\mathrm{O}_{3}\right)$, hydrogen peroxide $\left(\mathrm{H}_{2} \mathrm{O}_{2}\right)$, methyl hydrogen peroxide $\left(\mathrm{CH}_{3} \mathrm{OOH}\right)$, liquid water, temperature, pressure, and wind component velocities. $\mathrm{DMS}, \mathrm{SO}_{2}$, water vapor, and $\mathrm{O}_{3}$ were determined at $25 \mathrm{~Hz}$.

The entire suite of NCAR aerosol probes available for C-130 was deployed. In addition PASE investigators determined diameter and volatility of coarse aerosol $(0.15-10.0 \mu \mathrm{m})$, size and volatility of nucleation size aerosol $(0.01-0.3 \mu \mathrm{m})$, size resolved mixing state, volatile and nonvolatile number at $350^{\circ} \mathrm{C}$, ultrafine number concentration, absorption coefficient (Black Carbon), whitecap/bubble coverage, size integrated ambient total ions over the flight leg, leg average size resolved ions, coarse particle size distribution, fast submicron aerosol speciation heated and unheated CN (Clarke et al. 1999) supersaturation spectrum discussed in a subsequent section. Aerosol composition was determined with continuous measurements of non-refractory mass in sizes between 70 and $700 \mathrm{~nm}$ using an Aerodyne Aerosol Mass spectrometer (AMS) and using filter and impactor methods integrated over 30 min constant-altitude legs.

\subsection{Gases}

\subsubsection{DMS and SO2 chemical budgets}

Because of the fast instrumentation onboard the C-130 and the focused and repetitive flight strategy executed during PASE, careful scalar budgets were calculated for DMS, $\mathrm{SO}_{2}$, Ozone and water vapor using a multiple regression ordinary least squares fit to determine rates of change and horizontal gradients. After subtracting the budget contributions from the vertical turbulent fluxes and the horizontal mean advection (dynamical terms), the remaining time rate of change was shown to be due to any photochemical production and loss (or in the case of water, precipitation.) The DMS budget was consistent with oxidation solely by $\mathrm{OH}$ (Gray et al. 2010) with little room for significant $\mathrm{BrO}$ reactivity. For $\mathrm{SO}_{2}$, loss to aerosols was inferred from budget residuals for the night flights and then the bulk $\mathrm{SO}_{2}$ yield from DMS oxidation was found to be near unity from the day flights . Modeling analysis of the sulfur chemistry led to the hypothesis that the near unity yield may represent a source of $\mathrm{SO}_{2}$ independent of DMS, such as DMSO emitted directly from the ocean (Conley et al. 2009; Faloona et al. 2010; Gray et al. 2010). Further investigation of the budgets for ozone and water provided estimates of NOx levels of $\sim 10 \mathrm{pptv}$, and a mean precipitation rate of $\sim 1 \mathrm{~mm} \mathrm{~d}^{-1}$.

\subsubsection{DMS and $\mathrm{SO}_{2}$ concentration time dependence}

The daytime $\mathrm{SO}_{2}$ and DMS time series for RF05 are shown in Fig. 5. This time series was very similar to that observed by Bandy et al. (1996) although the PASE concentrations were 

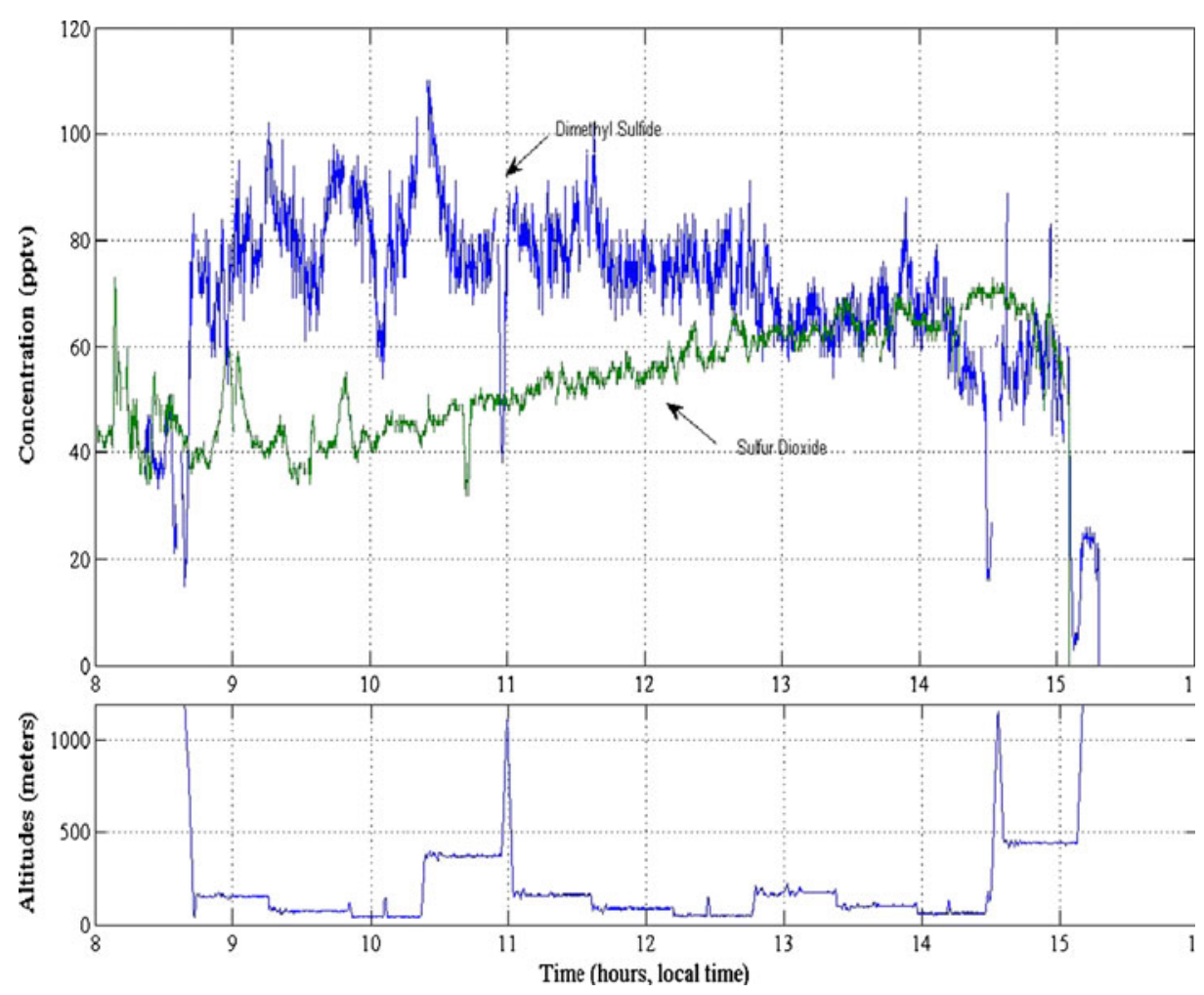

Fig. 5 RF05 time series for $\mathrm{SO}_{2}$ (green), DMS (blue), and altitude (bottom)

lower. DMS decreased from 82 to 65 pptv during a 5 hour period. Concurrently, the $\mathrm{SO}_{2}$ concentrations increased from about 42 to 70 pptv. Between 9 and 11 AM, DMS had significant fluctuations peaking at a concentration of 110 pptv. After 11 AM, DMS decreased linearly and much more smoothly until about 1500 when the mission ended. The $\mathrm{SO}_{2}$ concentration increased linearly and very smoothly beginning at 0930 . This increase

Fig. 6 RF05 Time series for afternoon $\mathrm{SO}_{2}$

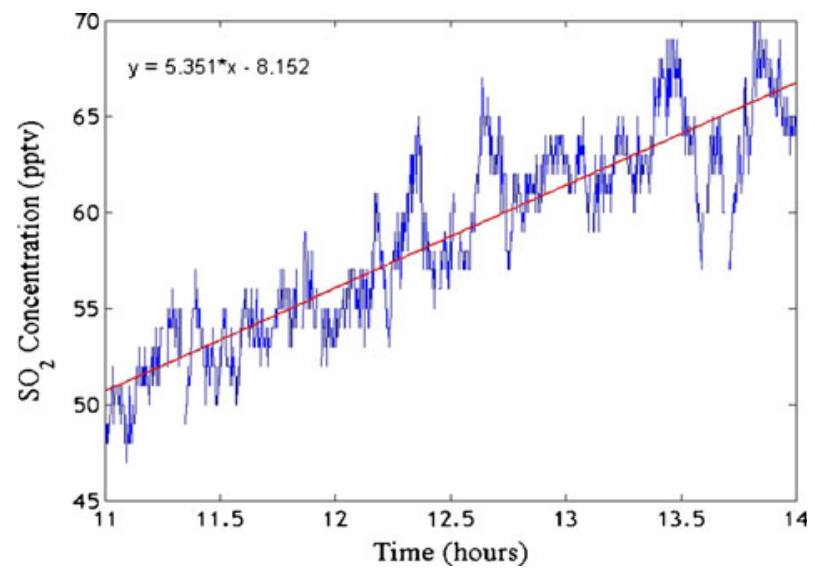


Fig. 7 Time series for the afternoon section of the DMS time series

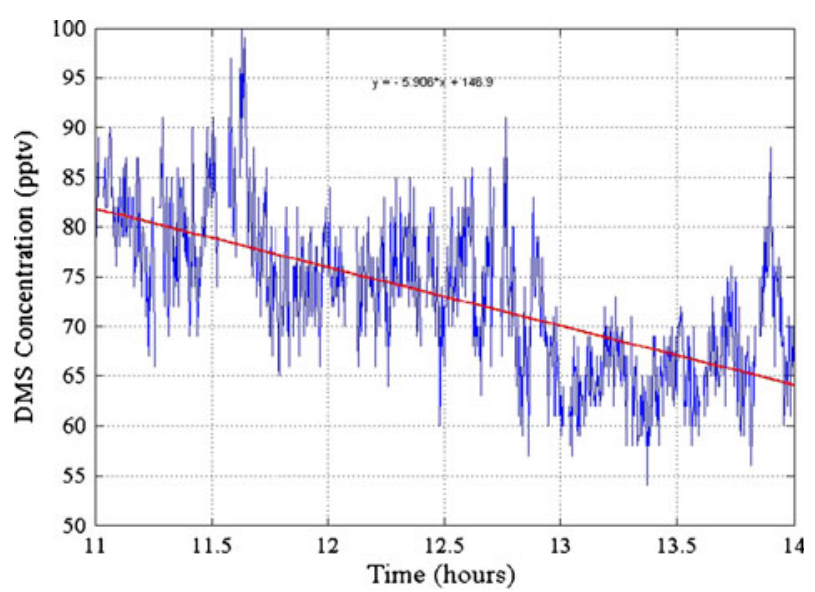

continued until 1450 when a rapid decrease began. The linear parts of the $\mathrm{SO}_{2}$ and DMS time series are shown in Figs. 6 and 7 respectively.

\subsection{3 $\mathrm{SO}_{2}$ and DMS behavior below $200 \mathrm{~m}$}

Profiles for DMS and $\mathrm{SO}_{2}$ below $200 \mathrm{~m}$ reveal little variation in the concentrations of these species near the sea surface. This means the concentrations alone contain limited information about the chemistry of these species in this region. In contrast, the $\mathrm{SO}_{2}$ flux becomes measurably more negative as the sea is approached (Fig. 8). Due to in-situ photochemical formation from DMS, the $\mathrm{SO}_{2}$ flux changes from negative to positive near $200 \mathrm{~m}$. The DMS flux was also computed every $200 \mathrm{~s}$ and showed little change with altitude below $200 \mathrm{~m}$.

\subsection{4 $\mathrm{OH}, \mathrm{H}_{2} \mathrm{SO}_{4}, \mathrm{HO}_{2}$ and $\mathrm{CH}_{3} \mathrm{SO}_{3} \mathrm{H}$}

Time series for these species are shown in Fig. 9 for RF05. The levels and time dependence of these species are very similar to those observed in PEM Tropics A and B. The structure of the $\mathrm{OH}$ follows solar intensity whereas $\mathrm{H}_{2} \mathrm{SO}_{4}$ has more structure indicating other variables are involved. The MSA levels depend weakly on solar intensity and are about a

Fig. 8 Vertical profile of the $\mathrm{SO}_{2}$ flux near the ocean surface. Unlike the DMS flux, the $\mathrm{SO}_{2}$ flux slowly decreases near the sea surface

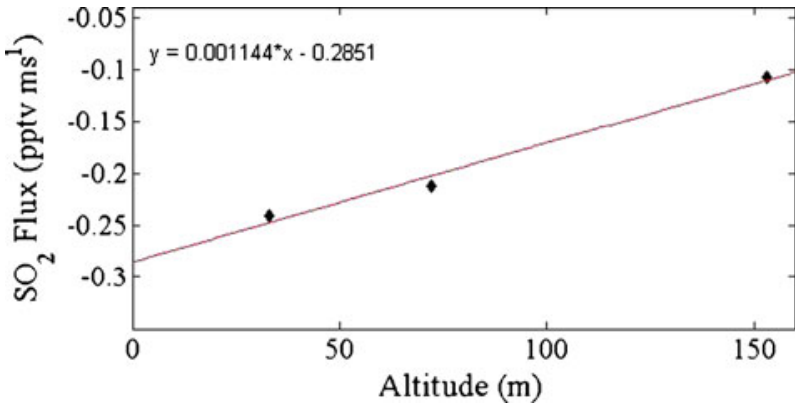



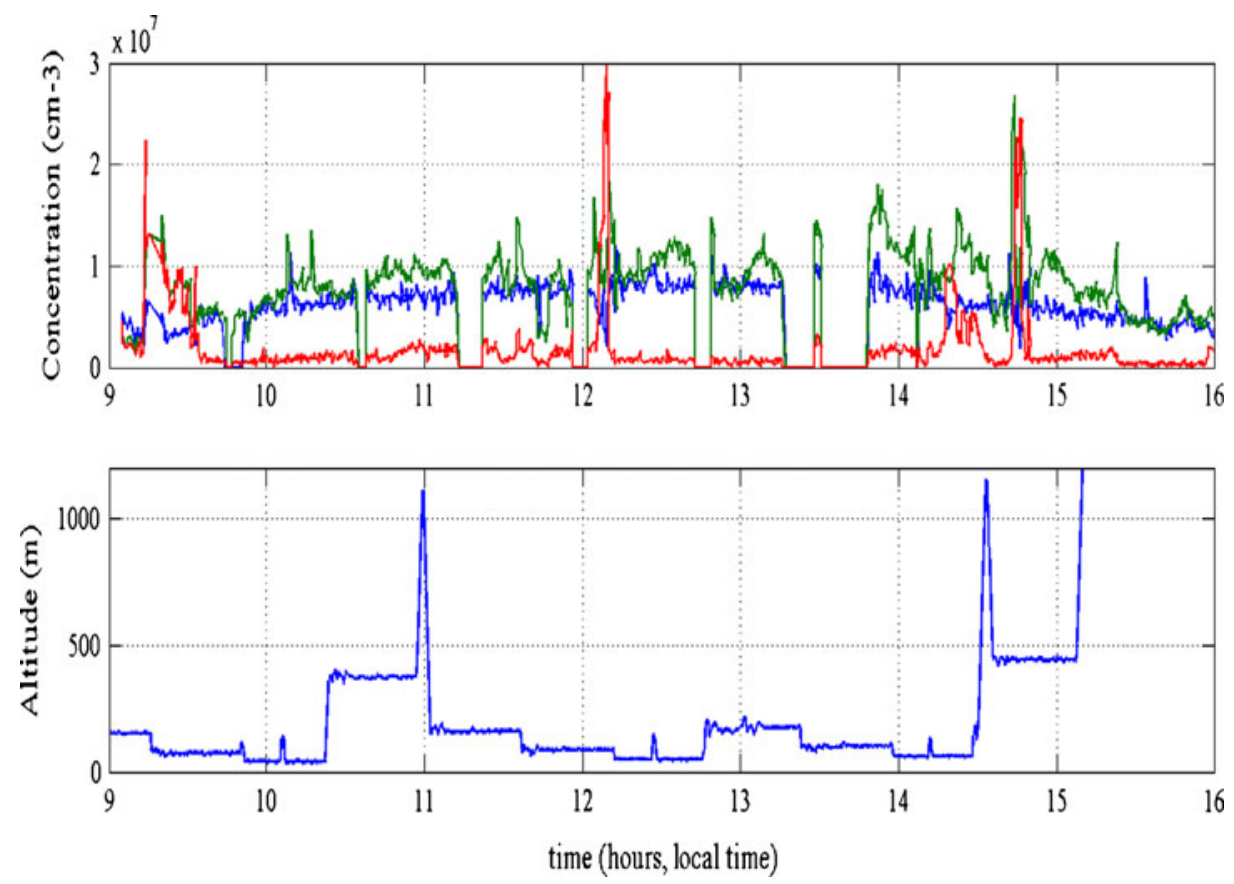

Fig. 9 Time series of $\mathrm{OH}, \mathrm{H}_{2} \mathrm{SO}_{4}, \mathrm{MSA}$ and altitude for RF05. Blue-OH, Green- $\mathrm{H}_{2} \mathrm{SO}_{4}$, Red-MSA

factor of 10 lower than $\mathrm{H}_{2} \mathrm{SO}_{4}$. There are several large peaks that appear to be uncorrelated to other species and meteorological parameters.

\subsection{5 $\mathrm{H}_{2} \mathrm{O}_{2}$ and $\mathrm{CH}_{3} \mathrm{OOH}$}

These species are formed by photochemical processes:

$$
\begin{gathered}
\mathrm{HO}_{2}+\mathrm{HO}_{2} \rightarrow \mathrm{H}_{2} \mathrm{O}_{2}+\mathrm{O}_{2} \\
\mathrm{CH}_{3} \mathrm{O}+\mathrm{CH}_{3} \mathrm{O} \rightarrow \mathrm{CH}_{3} \mathrm{OOH}+\mathrm{O}_{2}
\end{gathered}
$$

Time series for $\mathrm{H}_{2} \mathrm{O}_{2}, \mathrm{CH}_{3} \mathrm{OOH}$ and altitude for RF05 are shown in Fig. 10. Note that most of the time series are flown in the BL and that concentrations of both species are higher in the buffer layer. A small flux brings these species from the $\mathrm{BuL}$ to the BL. Surprisingly, $\mathrm{H}_{2} \mathrm{O}_{2}$ decreases during the daytime whereas $\mathrm{CH}_{3} \mathrm{OOH}$ only increases slightly. These data suggest that there is only a slight diurnal variation of these species in the BL.

\subsection{Aerosols}

\subsubsection{Aerosol size distribution}

Most aerosol properties of physical interest are expressed in their size distributions that contain their size resolved number, surface area or mass. These distributions were obtained 

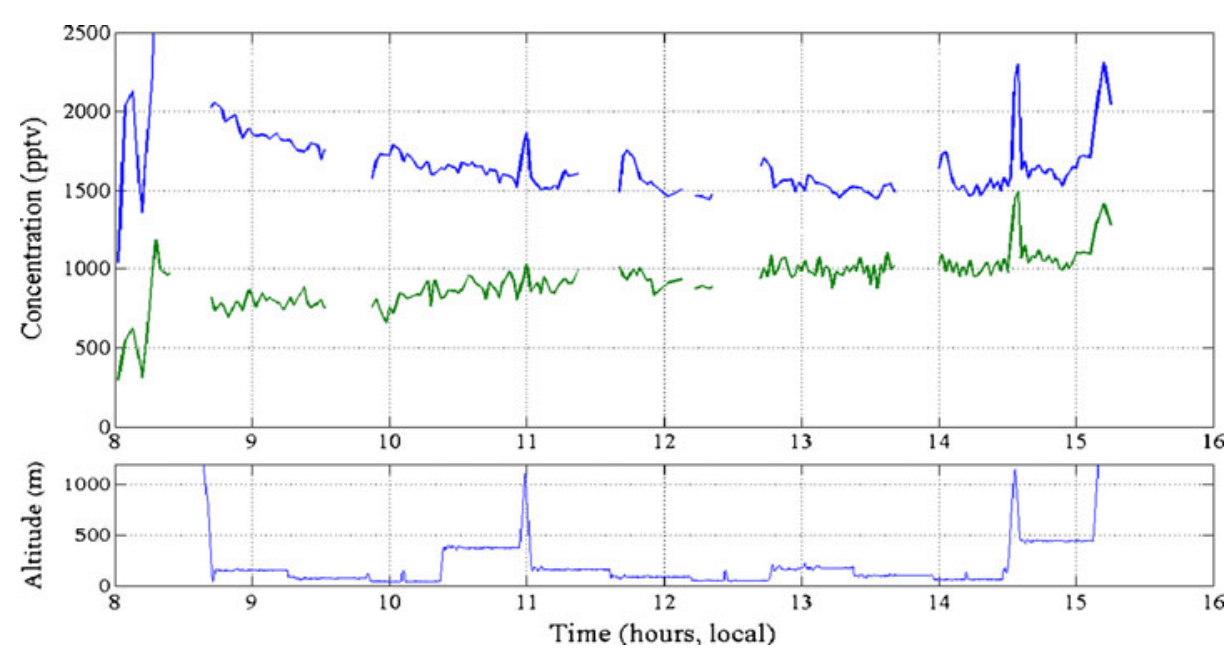

Fig. 10 Time series for $\mathrm{H}_{2} \mathrm{O}_{2}$ (blue) and $\mathrm{CH}_{3} \mathrm{OOH}$ (green) and altitude for $\mathrm{RF} 05$

for the dry $(<30 \% \mathrm{RH})$ aerosol every $1-3$ min depending upon the instrument used and whether it was operated using thermal conditioning or not. The vertical profiles of mean PASE aerosol number and area distributions below $3 \mathrm{~km}$ are shown as color coded profiles in Fig. 11. Note that the top of the BuL and the bottom of the FT is at approximately $1300 \mathrm{~m}$. The top of the $\mathrm{BL}$ and the bottom of the BuL is at approximately $400 \mathrm{~m}$ (see Fig. 3).

The distributions reported are merged dry distributions from the HiGEAR DMA, OPC and APS instrumentation. In spite of the variability possible at any time and altitude, the mean profiles reveal the main features of the PASE aerosol. Smallest particles are present in the FT with a number mode generally between 40 and $80 \mathrm{~nm}$ with a tendency to increase in mean size with proximity to the top of the BuL. Beginning in the FT, but even more evident in the MBL, the monomodal number peak is separated into a bimodal distribution with a
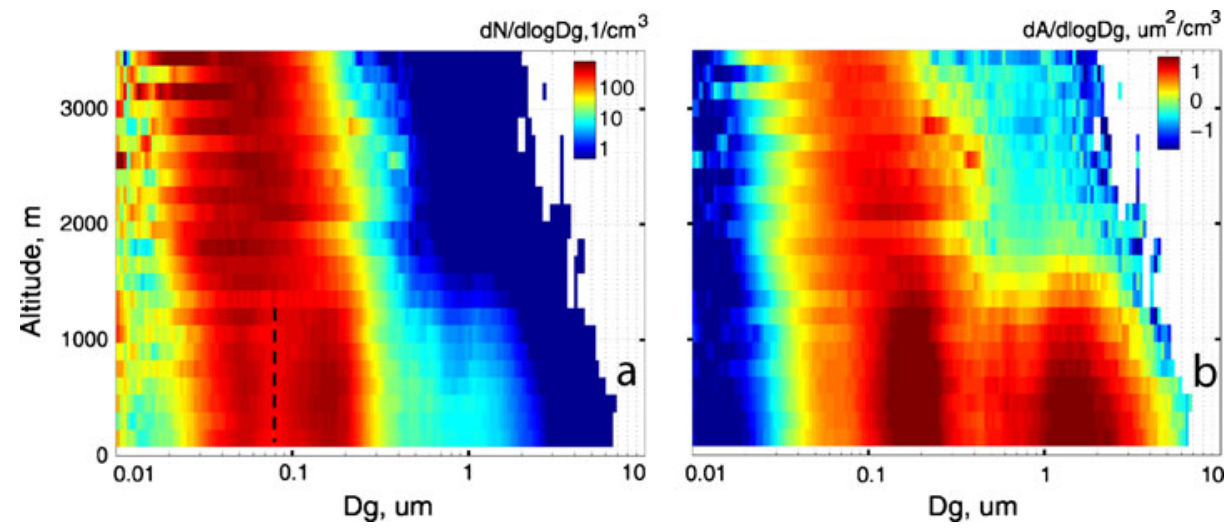

Fig. 11 Mean 2D vertical profiles of ambient number (left panel-colored by $\mathrm{dN} / \mathrm{d} \operatorname{logDp}$ ) and area (right panel-colored by $\mathrm{dA} / \mathrm{d} \log \mathrm{Dp}$ ) size distributions for all vertical profiles from PASE. The Hoppel minimumdotted line) reflects cloud processes separating activated ambient $\mathrm{CCN}$ to the right from unactivated sizes to the left 
minimum near about $90 \mathrm{~nm}$. This Hoppel minimum (Hoppel et al. 1994) is a result of activation of the sizes above the Hoppel minimum in BuL clouds. Activaton of these particles in the BuL clouds greatly increases their surface area relative to unactivated sizes and favors greater heterogeneous gas to particle conversion by aqueous reactions resulting in larger dry sizes upon cloud evaporation. This larger number mode that reveals the representative CCN sizes activated in typical BuL clouds during PASE while the smaller mode was not activated in cloud and grows much less. These more extensive size resolved data during PASE indicate few particles smaller than $30 \mathrm{~nm}$ are present in the MBL. This confirms earlier surface and airborne observations showing that nucleation was not evident in the equatorial MBL and that the Aitken mode aerosol in the FT along with direct injection of sea-salt provides the primary source of MBL aerosol number that then grow heterogeneously in the MBL via sulfur chemistry. The apparent small particles at cloud level near $800 \mathrm{~m}$ are a result of cloud droplet shatter on the aircraft inlet that contaminated some distributions.

Aerosol area distributions also support this interpretation. The Aitken mode in the FT has low surface area centered on sizes near $80 \mathrm{~nm}$. These sizes make up a small contribution to MBL aerosol at the lower range of surface area distributions. As mentioned, cloud processing favors adding mass to the larger sizes in this mode leading to bimodal number distributions and increased surface areas near $0.2 \mu \mathrm{m}$ in the BL. Additional significant surface area from sea-salt is evident near $1.5 \mu \mathrm{m}$. In the BuL the latter decreases with altitude relative to the accumulation mode. The latter also gradually trends to smaller diameters with altitude into the FT mode.

PASE HiGEAR aerosol measurements were performed on dried aerosol such that measured mass and areas were well defined for the chemical constituents. Ambient aerosol size, mass and surface area will be larger due to the uptake of water at ambient RH. The latter are retrieved from the size distributions based upon known growth dependencies for common species like sea-salt and sulfates.

The role of humidity in establishing the ambient "wet" aerosol surface area during PASE is shown in the mean vertical profile of aerosol surface area in Fig. 12. Dry size distributions were integrated for sizes below $0.5 \mu \mathrm{m}$ and sizes above $0.5 \mu \mathrm{m}$ to get the indicated surface areas (red). Below about 1,500 m sea-salt tends to dominate area and mass for $\mathrm{Dp}>0.5 \mu \mathrm{m}$ and both sea-salt and sulfate contribute to surface area for $\mathrm{Dp}<0.5 \mu \mathrm{m}$. Dry surface area is well mixed in the BL with total values near $60 \mu \mathrm{m}^{2} \mathrm{~cm}^{-3}$. However, the increase in RH with altitude leads to a maximum in ambient wet surface area totaling about $100 \mu \mathrm{m}^{2} \mathrm{~cm}^{-3}$ near $500 \mathrm{~m}$. Above $500 \mathrm{~m}$ surface area decreases steadily up to the top of the $\mathrm{BuL}$ and bottom of the FT near 1,500 m. Relative humidity also decreases similarly,

Fig. 12 PASE (all flights) altitude bin $(100 \mathrm{~m})$ average vertical profiles of dry $(\mathrm{RH} \sim 30 \%)$ / ambient (blue, red) and submicron (Dp $<0.5 \mu \mathrm{m}$, dashed lines) / total $(0.01<\mathrm{Dp}<10 \mu \mathrm{m}$, solid lines $)$

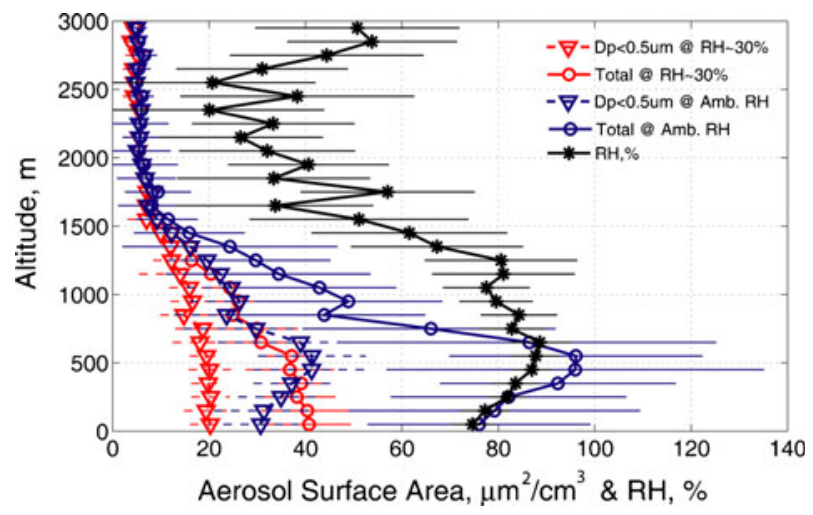

Aerosol Surface Area, $\mu \mathrm{m}^{2} / \mathrm{cm}^{3} \& \mathrm{RH}, \%$ 
reflecting the mixing of dry air entrained from the FT and moist air lofted from the BL by cloud processes. Above $1,500 \mathrm{~m}$ the dry surface area in the free troposphere is about $6 \mu \mathrm{m}^{2} \mathrm{~cm}^{-3}$. Once entrained through the TWR inversion, these values would increase by about a factor of two, depending upon actual humidity.

A time series of selected aerosol data is shown for RF05 in Fig. 13 along with size distributions averaged over the altitudes below $200 \mathrm{~m}$ for the initial and final stepped profiles. The time series shows non-volatile $\mathrm{CN}$ (CNhot-red) and volatile $\mathrm{CN}$ (CNvol-blue). As in previous figures, some variability over each leg is evident. The volatile CN (CNvol) are dominated by smaller sizes formed by gas to particle conversion. These are also generally not activated as $\mathrm{CCN}$ at low supersaturation in BuL clouds. CNhot generally indicates refractory aerosol like sea-salt and black carbon and larger sizes that are not fully volatilized. For example, a $10 \mathrm{~nm}$ residual remaining from heating a $200 \mathrm{~nm}$ aerosol represents a mass fraction of only 0.00125 . Sizes this small are detected by the CN counter but would not activate to be detected as $\mathrm{CCN}$ after heating. These larger sizes dominate CNhot and generally track closely with $\mathrm{CCN}$ at low supersaturations below about $0.4 \%$.

The time series of total surface area and surface area for sizes below 0.75 um diameter also show variability over each leg but also a decreasing trend during the flight. This is

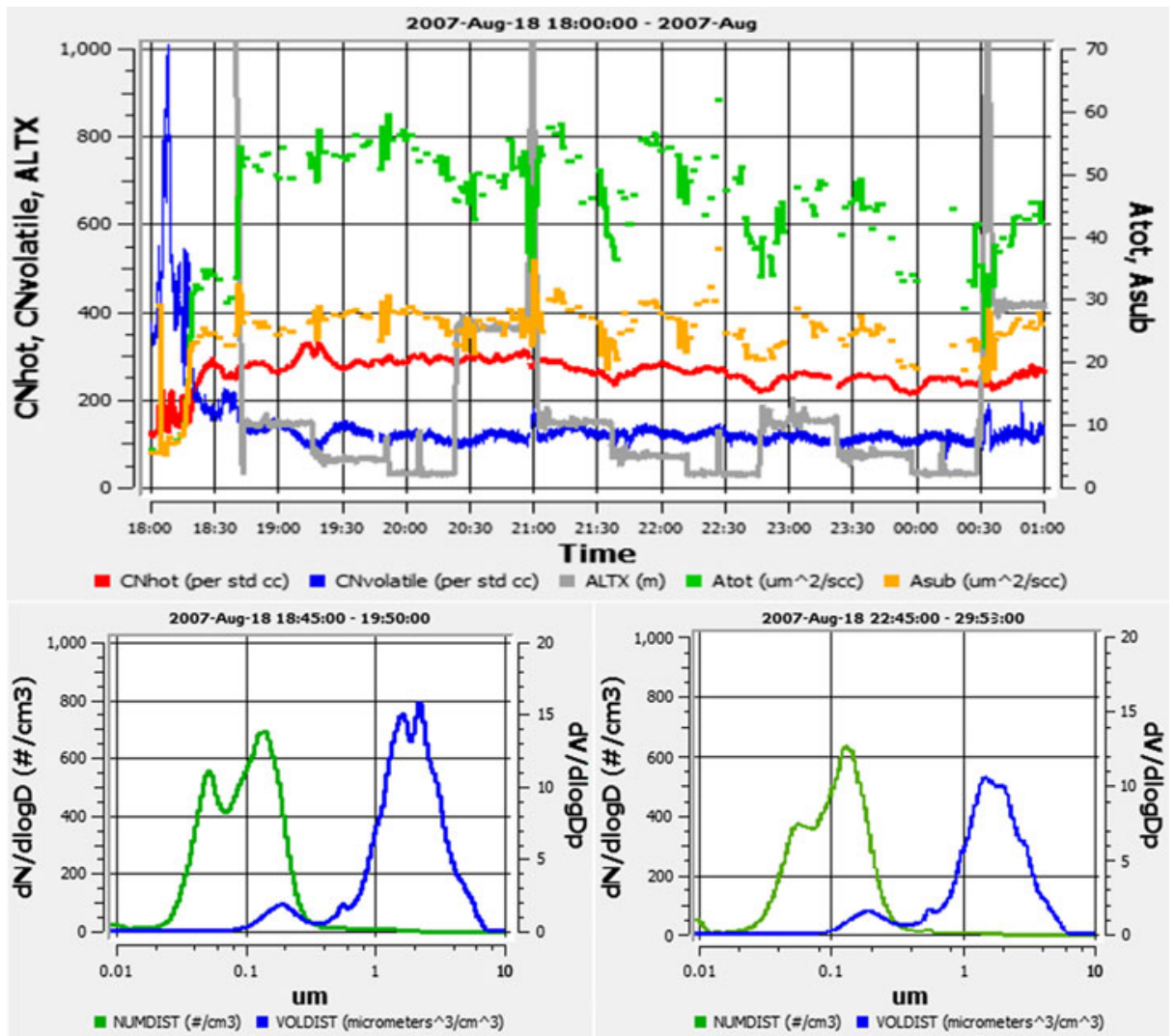

Fig. 13 Time series of volatile $\mathrm{CN}$ (CNvolatile), non-volatile $\mathrm{CN}$ (CNhot), total dry aerosol surface area (Atot) and area below $0.75 \mu \mathrm{m}$ diameter (Asub) for PASE RF05 along with dry number and surface area for indicated low altitude periods 
most evident for total surface area indicating sea-salt concentrations are decreasing. These RF05 surface areas start out somewhat larger than the means evident in Fig. 13 but end up closer to them. The size distributions for number and volume are also shown averaged over profiles between 18:45-19:50 and 22:45-23:59 for comparison. While distributions are generally similar, there is a clear decrease in the larger sea-salt volume over time but a much smaller decrease in accumulation mode number. There is also some indication of an increase in diameter for the Aitken mode (small peak below the Hoppel minima) possibly reflecting growth into the accumulation mode (adding to the typical $\mathrm{CCN}$ ). The latter has also decreased in number possibly due to cloud processing. The very small counts at smallest sizes are an artifact.

\subsubsection{Cloud Condensation Nuclei (CCN)}

BL CCN concentrations at $0.5 \%$ super saturation (S) averaged about $300 \mathrm{~cm}^{-3}$, which is higher than expected. Since no new particles were observed, as will be discussed in a subsequent section, the number of CCN did not increase with the amount of DMS present.

Continuous $\mathrm{CCN}$ concentrations were reported at 59 supersaturations ranging from 0.00195 to $0.5 \%$. A time series for a subset of these data is shown in Fig. 14. At the beginning of the mission, there were small increases of $\mathrm{CCN}$ at $\mathrm{S}$ with little variation for each section of the chevron. However, at $11 \mathrm{~h}$ the aircraft executed a 90-270 turn which included a profile through the BuL and BL. Following this change in track, the time series seems to have sinusoidal variations along the track. However the CCN concentrations increase until $11 \mathrm{AM}$ after which they decline throughout the remainder of the day until the end of the experiment at 14:30. No dependence of CCN on altitude was observed in the BL.
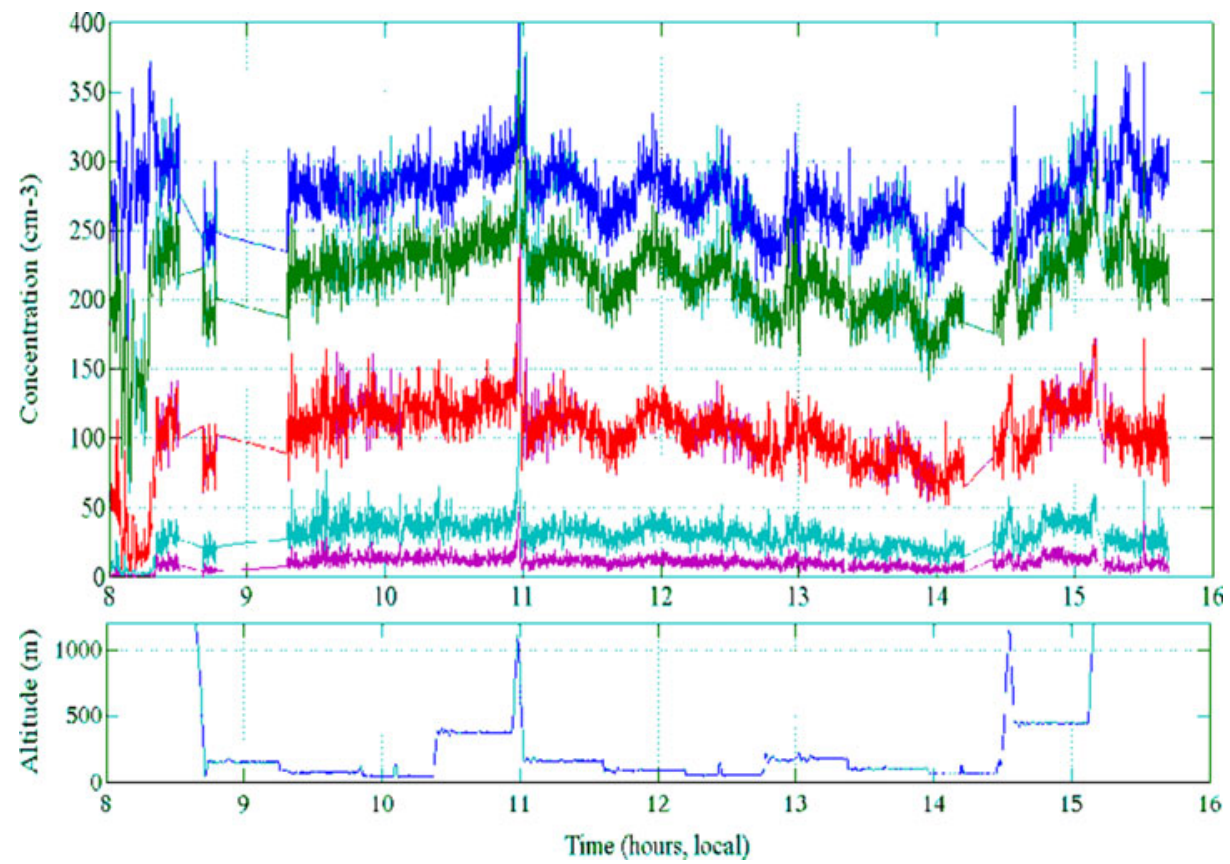

Fig. 14 CCN time series for RF05. Super saturations: Purple-0.0095, Aqua- 0.027, Red-0.072, Green-0.225, Blue- 0.5 


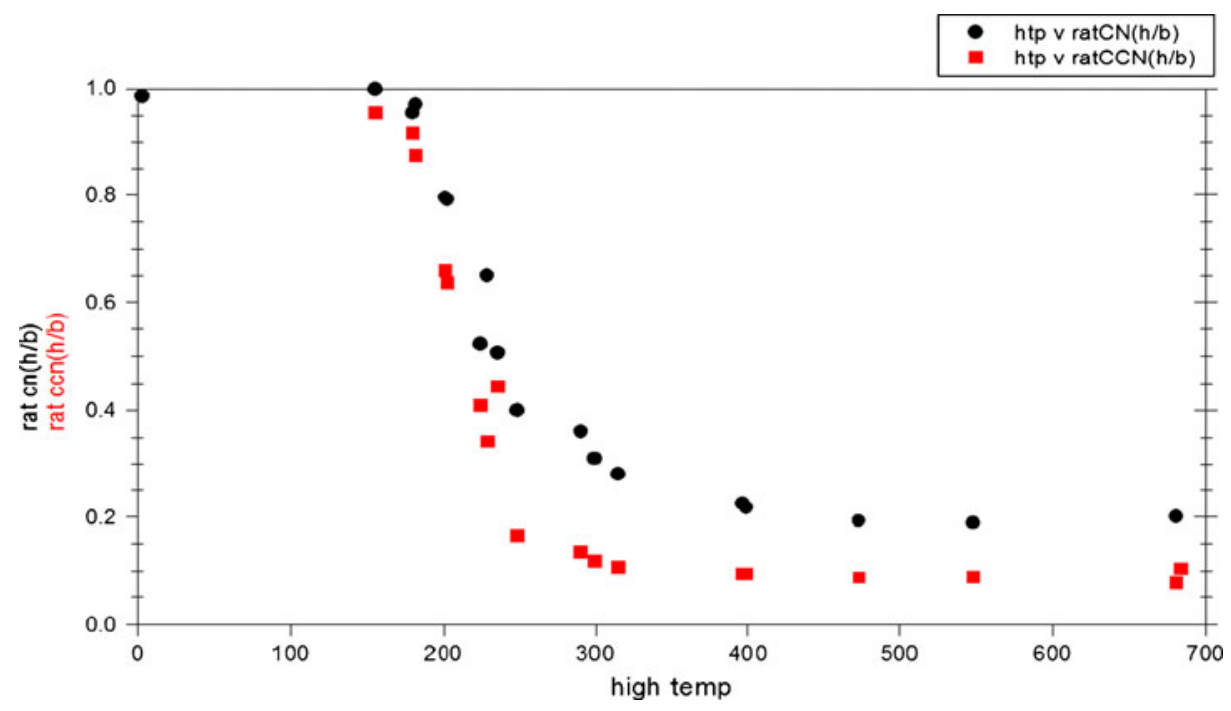

Fig. 15 Thermal properties of CCN (red) and CN (black). Red is the fraction of CCN remaining and black is the fraction of the $\mathrm{CN}$ remaining at the indicated temperature

The thermal characteristics the $\mathrm{CCN}$ and $\mathrm{CN}$ are shown in Fig. 15. Both the $\mathrm{CN}$ and $\mathrm{CCN}$ are mostly volatile probably because they are often largely composed of particles produced from $\mathrm{H}_{2} \mathrm{SO}_{4}$ and $\mathrm{NH}_{3}$ although other volatile components may at times be present and influence $\mathrm{CCN}$ properties. A few particles remain that are nonvolatile at 300 degrees that include sea-salt, black carbon and residues of larger particles not fully volatilized. The number of nonvolatile $\mathrm{CN}$ is about double the number of nonvolatile $\mathrm{CCN}$ largely because these smallest residual sizes will not activate at typical supersaturations and will not be identified as CCN.

\subsubsection{Search for the formation of new particles}

$\mathrm{CN}$ and CCN levels in PASE were very high relative to some similar systems like the one studied in the Rain in Cumulus over the Ocean experiment (RICO). Cloud and rain in RICO obviously explain some but not all of the differences. A popular model for aerosol in the trade wind system is that FT particles are transported to the top of the marine trade wind system by strong subsidence and then entrained into the BuL. However, observations in RICO indicated that they came from the cloud layer. In the $\mathrm{BuL}$ and $\mathrm{BL}$, these particles accrete water and $\mathrm{H}_{2} \mathrm{SO}_{4}$ thus forming large and more reactive particles.

Of importance is the observation that $\mathrm{CN}$ concentrations are about the same in the BuL and BL. This supports the idea that the aerosol lifetime in the trade wind system is a few days allowing particles to move between $\mathrm{BL}$ and BuL many times during their lifetime. Comparatively the sulfur gases have such a short lifetime that once formed they move only once to another layer if at all. This leads to the large concentration jumps at the interface between the BL and BuL $\mathrm{An}$ exception can occur if the aerosol contains a volatile component like methane sulfonate. This component has dramatically different chemistry in the BuL than in the BL.

Also of importance is that aerosol and gases in the trade wind regimes do not get out by moving back into the FT which is demonstrated with the observation that no DMS is 
observed just above the BuL top. Once in the trade wind system they stay there until removed by convection, chemistry or dry deposition.

\subsubsection{Aerosol composition}

Total aerosol was collected and analyzed by ion chromatography. Although several ions were determined, emphasis here is on sea salt sulfate (SSA) and NSSA for RF05. A time series for these quantities is shown in Fig. 16. Ignoring the outliers at $13 \mathrm{~h}$, both SSA and NSSA are constant within the precision of the data. Time series for sulfate and ammonium ion obtained by Aerosol Mass Spectrometer are shown in Fig. 17. Although less accurate than the whole sample analysis, the sample rate is much higher. It appears that the $\mathrm{SO}_{2}$ lost to aerosol is not large enough to appear in these data.

Also of interest is the variation of these quantities as a function of time of day. Time series of SSA and NSSA using data from all flights are shown in Figs. 18 and 19 (UTC time) respectively. Inspection of these data reveals that SSA decreases during the day, consistent with above time series of coarse surface area whereas the NSSA does not.

The ratio of bromine for all flights plotted as a function of fraction of a day is shown in Fig. 20. The mass ratio varies between 0.0015 and 0.0025 . Most interesting is the observation that bromine appears to be lost during the daytime although it is small.

\subsection{Modeling analysis}

To help interpret the observational data, the 1-D version of the Regional chEmical trAnsport Model (REAM) (Choi et al. 2008; Zhao et al. 2009) was applied to simulate HOx and sulfur chemistry and the vertical exchange among the boundary layer, buffer layer, and lower free troposphere. On average, model simulated $\mathrm{OH}$ and $\mathrm{HO}_{2}$ concentrations are in reasonable agreement with the observations (within 20-30\%) when observed $\mathrm{O}_{3}$ and peroxides are specified in the model.

A sulfur module was added to the standard version of REAM. The modeled species were DMS, $\mathrm{SO}_{2}$, dimethyl sulfoxide (DMSO), methane sulfinic acid (MSIA), methane sulfonic

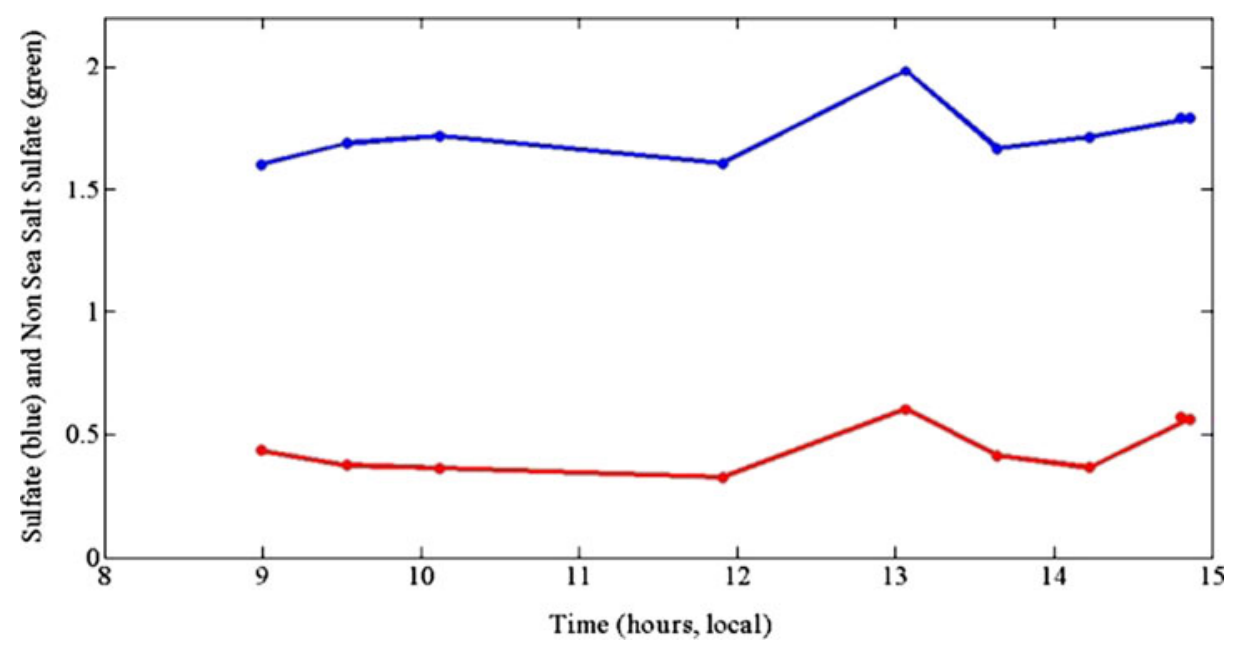

Fig. 16 Sea salt sulfate (blue) and non sea salt sulfate (red) in $\mu \mathrm{g} \mathrm{m}{ }^{-3}$ for RF05 


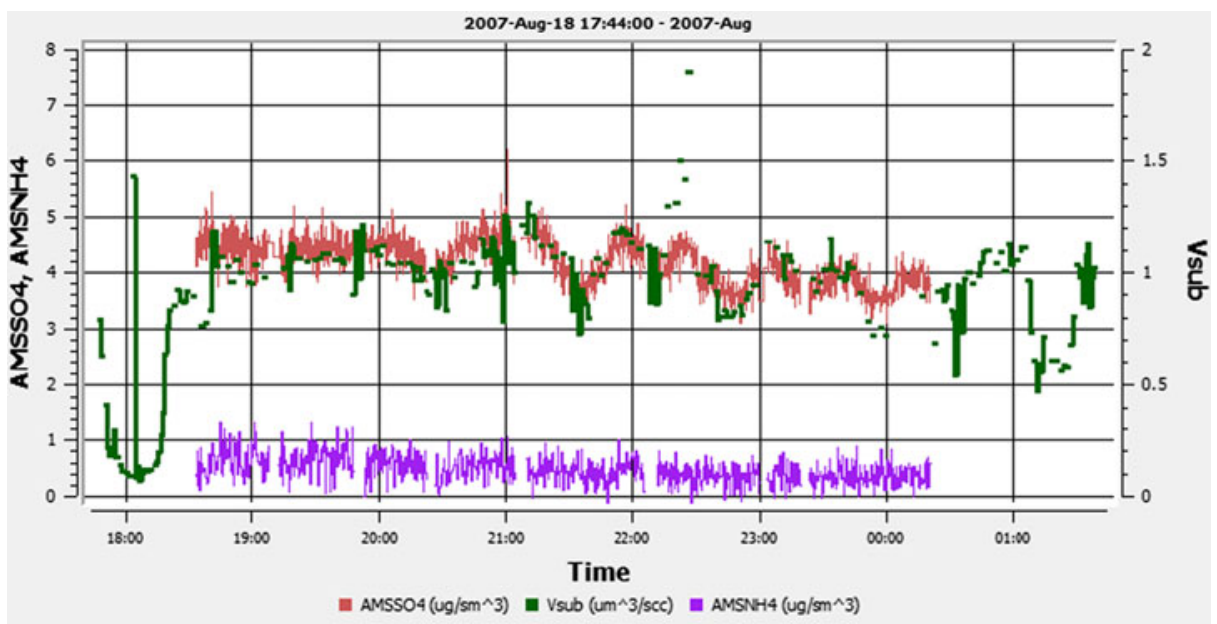

Fig. 17 RF05 time series for sulfate and ammonium using Aerosol Mass Spectrometry. Vsub is the aerosol volume

acid (MSA), and sulfuric acid $\left(\mathrm{H}_{2} \mathrm{SO}_{4}\right)$. For DMS and $\mathrm{SO}_{2}$ distributions, their vertical transport was shown to be critically important. During the PASE experiments, it was dominated by turbulent transport. The respective vertical distributions of these species were simulated well in both the $\mathrm{BL}$ and $\mathrm{BuL} . \mathrm{SO}_{2}$ within the $\mathrm{BL}$ and $\mathrm{BuL}$ is primarily produced from DMS oxidation by $\mathrm{OH}$. However, the observational data do not preclude
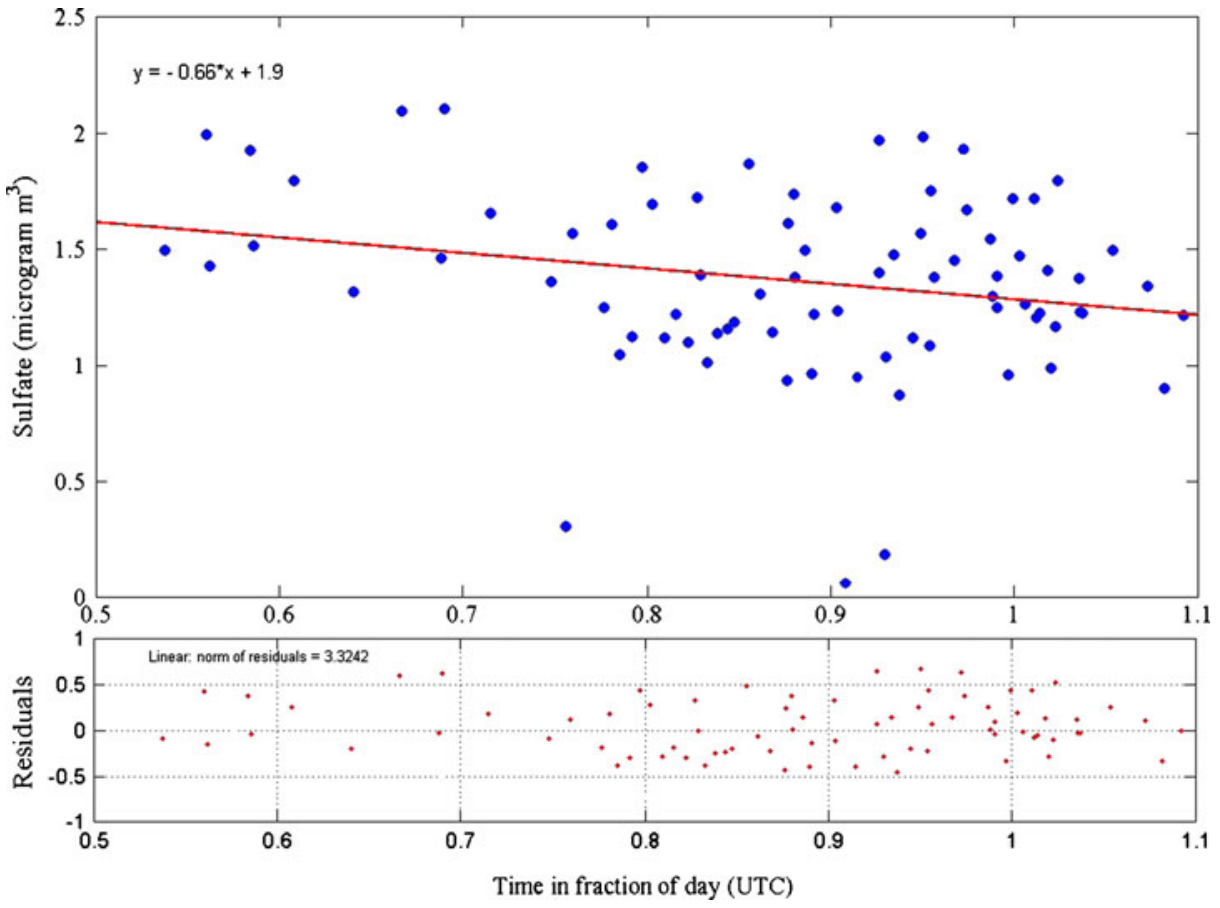

Fig. 18 RF05 Sulfate as a function of time of day UTC (all flight) 

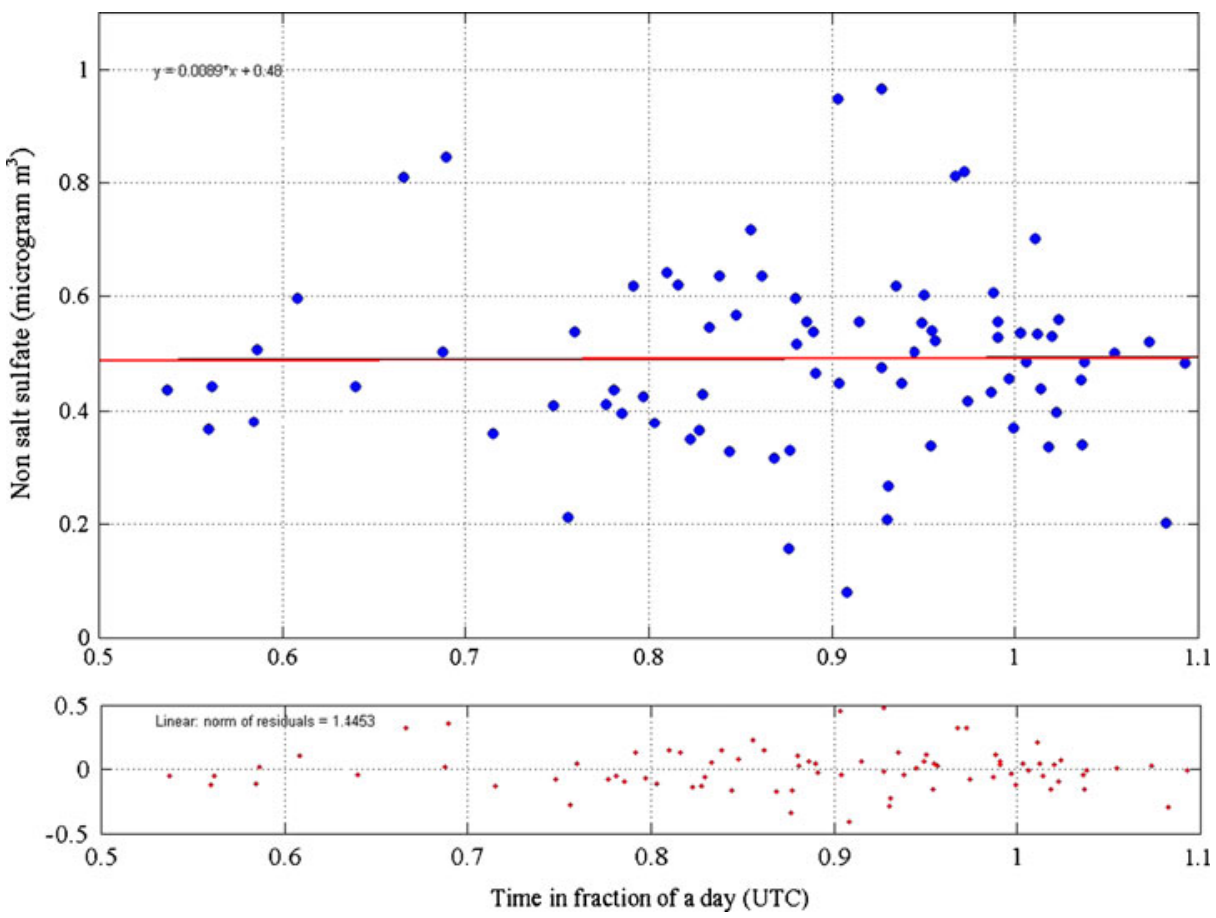

Fig. 19 Non sea salt sulfate as a function of time of day UTC (all flights)
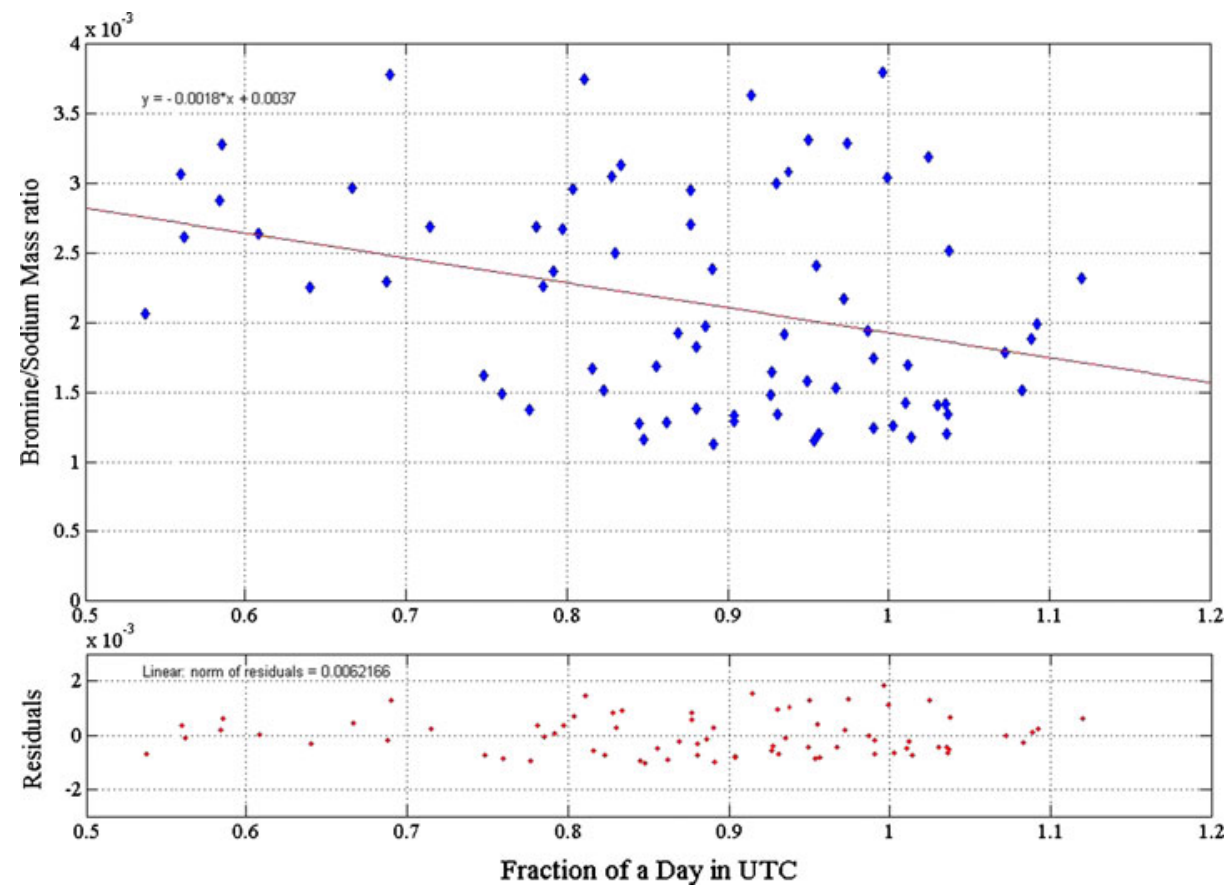

Fig. 20 Bromine/Sodium mass ratio as a function of fraction of a day 
the possibility that as much as 1 pptv of BrO may also serve as a DMS oxidant. In the lower free troposphere, there is significant evidence suggesting that long-range transport may also be important in defining the levels of $\mathrm{SO}_{2}$ observed. In the absence of other chemical oxidants, the average DMS-to- $\mathrm{SO}_{2}$ conversion efficiency was estimated at $\sim 73 \%$. Adding 1 pptv $\mathrm{BrO}$ to the atmospheric mix shifts this yield downward to $60 \%$. Removal pathways were found to differ drastically in the BL versus the BuL. In the $\mathrm{BL}$, deposition is the largest sink for $\mathrm{SO}_{2}(48 \%)$; aerosol scavenging and transport into the buffer layer each contributes $\sim 19 \%$, and $\mathrm{OH}$ oxidation removes $14 \%$. In the BuL, cloud scavenging is the largest sink (85\%) with the remaining $15 \%$ lost by $\mathrm{OH}$ oxidation. The dry deposition flux measured during PASE was approximately one-half that predicted by the resistance-in-series scheme developed by (Wesely 1989), implying a significant overestimation of $\mathrm{SO}_{2}$ dry deposition in current 3-D chemical transport models when used over tropical oceans.

The model estimate of the DMS to $\mathrm{SO}_{2}$ conversion efficiency, based on known kinetics data and PASE measurements, was found to be in quite good agreement with previous field studies when the focus has been specifically on tropical marine environments . The range of these values, however, was significantly lower than the near unity yield derived indirectly through a budget study reported by Faloona et al (2010), who also used PASE measurements as a basis for their calculations.

\section{Conclusions}

\subsection{Aerosol and sulfur chemistry}

An overall goal of PASE was to establish a connection between the chemistry of DMS and the cloud properties. In the PASE BL the Hoppel minimum revealing the separations between activated and non-activated aerosol in typical MBL clouds was near $80 \mathrm{~nm}$. Aerosol distributions entrained from the FT straddled that size with often $20-40 \%$ being larger than $80 \mathrm{~nm}$ and able to be activated directly as CCN.

Over time some of smaller FT sizes converted to larger CCN size particles by sulfur chemistry and hydration. PASE observations clearly show a connection between sulfur chemistry aerosol growth and the formation of cloud condensation nuclei that can activate to cloud droplets.

PASE has provided new information and insights that lead to a better understanding of trade chemistry and dynamics. It also provided the basis for future studies that includes the buffer layer $(\mathrm{BuL})$ and free troposphere $(\mathrm{FT})$ as well as the boundary layer $(\mathrm{BL})$. However, the limited studies of the BuL and FT led to a better understanding of these layers that will be valuable in the planning and execution of future studies.

\subsection{PASE TWR}

Research following the PASE study revealed that the PASE trade-wind study region (TWR) was characteristic of a TWR region from southwest of Galapagos to Christmas Island and beyond. This region has a very low albedo and high solar irradiance so is a region of intense solar heating of earth. Very few clouds exist but what clouds are present can have an important effect on surface heating. Because of the large size of the region the connection between cloud properties and sulfur chemistry must be carefully parameterized. 


\section{3 $\mathrm{SO}_{2}$ conversion efficiency}

As expected the chemistry of sulfur in the trade winds was found to be initiated by the emission of DMS into the BL of the tropical Trade Wind regime. However, the efficiency with which this DMS is converted to $\mathrm{SO}_{2}$ has been brought into further question by this study. This unusual result has come about as a consequence of our using two totally different approaches for addressing this long standing question. In the first approach, based on accepted kinetic rate constants and detailed steps for the oxidation of DMS reflecting detailed laboratory studies, an $\mathrm{SO}_{2}$ conversion efficiency of $60-73 \%$ was determined (Gray et al. 2010).

This range of values lies well within the uncertainties cited in five other independent studies also focused on the tropical Pacific (Gray et al. 2010; Davis 2011, unpublished results). However, using a completely different approach, involving a budget analysis, a conversion value of $100 \%$ was estimated by Faloona et al. (2010). The latter value, to be consistent with all other sulfur studies, requires the existence of a completely independent sulfur source which would emit into the atmosphere a source strength approximately half that measured for DMS under tropical Pacific conditions. At this time, however, there is no credible scientific observation that identifies what this source might be. Thus, the current study has opened for future scientific investigation the major question: Is there yet another major tropical marine source of sulfur? Of equal importance, then, is the related question, is our global sulfur budget significantly in error due to the existence of an unknown marine source of sulfur? Pivotal to both questions may be gaining greater insight about the intermediate DMS oxidation species, DMSO, for which rather unusual dmso concentration data have been reported in previous marine sulfur studies (Bandy et al. 1996; Nowak et al. 2001).

\subsection{Bromine chemistry}

The 3 pptv bromine deficit observed must be lost over the lifetime of the aerosol which is a few days. This observation suggests that the primary BrO production rate is very small. However, considering the uncertainties in these observations and the possible importance of secondary production of bromine radicals through aerosol surface reactions, to completely rule out the importance of bromine chemistry under tropical conditions at this time cannot be justified. This point has been brought into focus from the work reported by Gray et al. (2010) where it was shown that even at levels of 1 pptv, the effect of $\mathrm{BrO}$ oxidation on DMS can still be quite significant. Thus, as in the case of DMS conversion to $\mathrm{SO}_{2}$, future studies will be needed. In the latter case there will need to be a specific focus on halogen chemistry. Such studies will clearly need to involve specific measurements of radical species such as BrO.

Open Access This article is distributed under the terms of the Creative Commons Attribution License which permits any use, distribution, and reproduction in any medium, provided the original author(s) and the source are credited.

\section{References}

Bandy, A., Thornton, D.C., Blomquist, B.W., Chen, S., Wade, T.P., Ianni, J.C., Mitchell, G.M., Nadler, W.: Chemistry of dimethyl sulfide in the equatorial pacific atmosphere. Geophys. Res. Lett. 23(7), 741-744 (1996) 
Barnard, W.R., Andreae, M.O., Watkins, W.E., Bingemer, H., Georgii, H.W.: The flux of dimethylsulfide from the oceans to the atmosphere. J. Geophys. Res. 87(C11), 8787-8793 (1982)

Charlson, R.J., Lovelock, J.E., Andreae, M.O., Warren, S.G.: Oceanic phytoplankton, atmospheric sulfur, cloud albedo and climate. Nature 326, 655-661 (1987)

Chen, G., Davis, D.D., Kasibhatla, P., Bandy, A.R., Thornton, D.C., Huebert, B.J., Clarke, A.D., Blomquist, B.W.: A study of DMS oxidation in the tropics: comparison of christmas island field observations of DMS, $\mathrm{SO}_{2}$, and DMSO with model simulations. J. Atmos. Chem. 37(2), 137-160 (2000)

Choi, Y., Wang, Y., Zeng, T., Cunnold, D., Yang, E.S., Martin, R., Chance, K., Thouret, V., Edgerton, E.: Springtime transitions of no2, co, and o-3 over north america: model evaluation and analysis. J. Geophys. Res. Atmos. 113(D20), (2008).

Clarke, A.D., et al.: Particle nucleation in the tropical boundary layer and its coupling to marine sulfur sources. Science 282, 89-92 (1998)

Clarke, A., Eisele, F., Kapustin, V., Moore, K., Tanner, D., Mauldin, L., Litchy, M., Lienert, B., Carroll, M., Albercook, G.: Nucleation in the equatorial free troposphere: favorable environments during pem-tropics. J. Geophys. Res. 104(D5), 5735-5744 (1999)

Conley, S.A., Faloona, I., Miller, G.H., Lenschow, D.H., Blomquist, B., Bandy, A.: Closing the dimethyl sulfide budget in the tropical marine boundary layer during the pacific atmospheric sulfur experiment. Atmos. Chem. Phys. 9(22), 8745-8756 (2009)

Davis, D., et al.: Dimethyl sulfide oxidation in the equatorial pacific: comparison of model simulations with field observations for DMS, $\mathrm{SO}_{2}, \mathrm{H}_{2} \mathrm{SO}_{4}(\mathrm{~g}), \mathrm{msa}(\mathrm{g}), \mathrm{MS}$ and nss. J. Geophys. Res. 104(D5), 5765-5784 (1999)

Faloona, I., Conley, S.A., Blomquist, B., Clarke, A.D., Kapustin, V., Howell, S., Lenschow, D.H., Bandy, A. R.: Sulfur dioxide in the tropical marine boundary layer: dry deposition and heterogeneous oxidation observed during the pacific atmospheric sulfur experiment. J. Atmos. Chem. 63(1), 13-32 (2010)

Gray, B.A., Wang, Y., Gu, D., Bandy, A., Mauldin, L., Clarke, A., Alexander, B., Davis, D.D.: Sources, transport, and sinks of $\mathrm{SO}_{2}$ over the equatorial pacific during the pacific atmospheric sulfur experiment. J. Atmos. Chem. (2010).

Hoppel, W.A., Frick, G.M., Fitzgerald, J., Larson, R.E.: Marine boundary-layer measurements of new particle formation and the effects nonprecipitating clouds have on aerosol-size distribution. J. Geophys. Res. Atmos. 99(D7), 14443-14459 (1994)

Huebert, B.J., Wylie, D.J., Zhuang, L., Heath, J.A.: Production and loss of methanesulfonate and non-sea salt sulfate in the equatorial pacific marine boundary layer. Geophys. Res. Lett. 23(7), 737-740 (1996)

Nowak, J.B., et al.: Airborne observations of DMSO, DMS, and oh at marine tropical latitudes. Geophys. Res. Lett. 28(11), 2201-2204 (2001)

Wesely, M.L.: Parameterization of surface resistances to gaseous dry deposition in regional-scale numerical-models. Atmos. Environ. 23(6), 1293-1304 (1989)

Zhao, C., Wang, Y., Choi, Y., Zeng, T.: Summertime impact of convective transport and lightning nox production over north america: Modeling dependence on meteorological simulations. Atmos. Chem. Phys. 9(13), 4315-4327 (2009) 